\title{
US food-safety body hears protests over genetically modified food
}

\section{The US Food and Drug Administration is holding public meetings to listen to critics of genetically modified food. Some fear the move may backfire.}

\section{Washington}

The US Food and Drug Administration (FDA), faced with increasingly vocal consumer protests about its regulation of genetically modified (GM) food, is undertaking an unprecedented programme of public consultations aimed at reassuring its critics.

But many critics remain unconvinced, and it is not clear whether the consultations will relieve public concern or intensify it.

The FDA's good name with the US public is widely regarded as a major factor in the rapid and, until this year, unobtrusive arrival of genetically modified soy and maize into the US food chain. But US environmental activists and consumer groups have recently been working hard to cultivate the kind of public backlash that has blocked GM foods in some European countries.

In October, the FDA responded by announcing that it would seek to "engage the public about foods using bioengineering" at large public meetings in Chicago on 18 November, in Washington on 30 November, and in Oakland, California, on 13 December.

Attempting to relieve public criticism through high-profile public debate was always going to be a risky strategy, however, as the first two meetings have shown. Even as they applaud the openness of the process, the FDA's critics have made full use of it to intensify their attacks on its integrity.

\section{Inviting criticism}

The format of the meetings has been criticized by some participants because public comment - from dozens of people, given two minutes each - took place late in the day, after FDA officials and discussion panels had spoken, and when most television cameras and reporters had left.

However, the FDA has ensured that critics of biotechnology are represented on its discussion panels. At the Washington meeting, for example, half of a six-strong panel discussing 'science, safety and regulatory issues' were generally opposed to the use of GM foods. One, Steven Druker of the Alliance for Bio-Integrity, is suing the FDA to demand labelling and more safety testing of GM foods.

"I'm surprised to be here, and the fact that I am suggests that the FDA is open to all sides

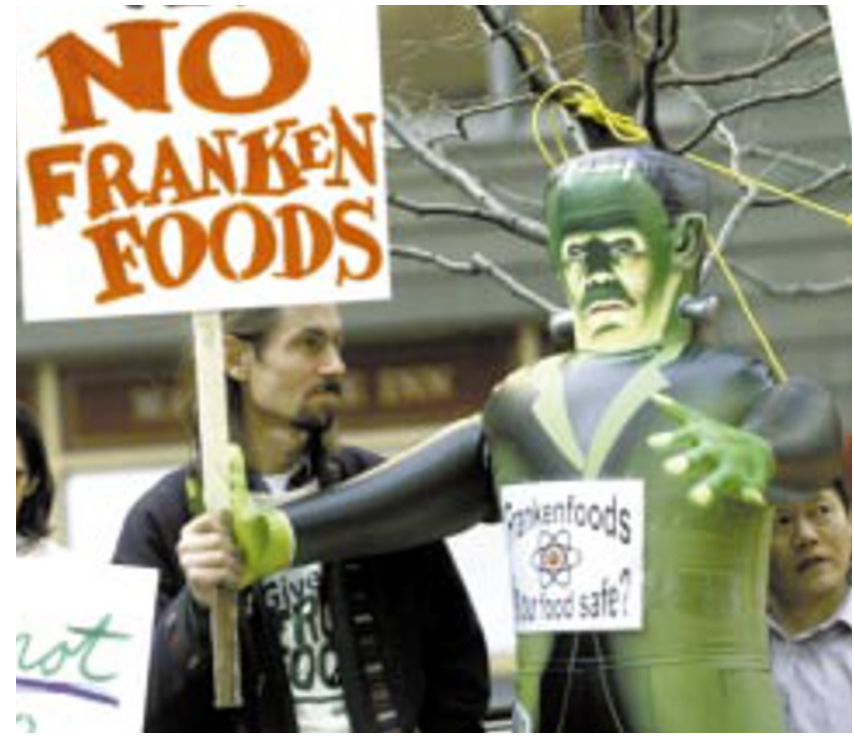

Made for TV: the meeting in Chicago provided an opportunity for demonstrators to make their point on television.

of the argument, and may be open to change," Druker said at the panel discussion, which was dominated by attacks on the FDA's position.

For example, Carol Foreman, director of food policy at the Consumer Federation of America, charged that the FDA's current voluntary policy for regulating GM foods was developed in 1992 "as part of the regulatory relief programme" of president George Bush.

James Maryanski, the FDA's food biotechnology coordinator, hotly denies this. "I can assure you that our policy was developed by FDA scientists," he says. But although Maryanski says he remains open to any information that emerges at the final meeting and from written comments that the agency has also invited, he says that, so far, "we haven't heard anything that would call for a substantial change in our scientific approach" to the regulation of GM foods.

Joseph Mendelson of the Center for Food Safety thinks that the most likely outcome of the consultation process will be that the FDA will make mandatory the existing voluntary system for regulating GM foods. Under this, industry and FDA scientists confer to identify any special cause for concern about a proposed genetic modification. Such action won't satisfy the critics, who want far tighter regulation based on extensive safety testing for each genetic modification.
Scientists involved in the panel discussions, such as Peter Day, head of the biotechnology centre at Rutgers University, New Jersey, applauded the FDA's process. "I admire what they are doing," he says. "If you are going to be credible, you've got to include the whole spectrum of opinion."

\section{Extensive coverage}

Industry representatives had called for the FDA to explain itself to the public, and those who spoke at the Washington meeting also lauded the process. But it is by no means clear that industry will benefit from it.

Extensive television and newspaper coverage of both the Chicago and Washington meetings tended to reflect the colourful antiGM demonstrators outside and the equally colourful anti-GM arguments within. The latter ranged from papers, produced by Druker, showing that the 1992 FDA regulations were subject to fierce internal debate, and allegations from the floor that cows are refusing to eat GM maize feed.

"You've got to wonder why the FDA is doing this, when it provides an avenue for them to take such a beating," reflects Mendelson. Part of the answer is that the GM food debate is providing a stiff and unusually sophisticated challenge to the agency's credibility. Agency officials hope that their response will be sufficiently open, and convincing, to maintain the US public's faith in GM foods - and in the FDA.

Colin Macilwain 